\title{
Tegumentary leishmaniasis and sand flies in a border area between Argentina and Bolivia
}

\author{
Griselda N. Copa ${ }^{a, b}$, María C. Almazán ${ }^{a, b}$, Lorena V. Aramayo ${ }^{b}$, Alejandro J. Krolewiecki ${ }^{a}$, Silvana P. Cajal ${ }^{a}$, \\ Marisa Juarez ${ }^{\mathrm{a}}$, Juan J. Lauthier ${ }^{c}$, Masataka Korenaga $^{c}$, Paola Barroso ${ }^{d}$, Julio R. Nasser ${ }^{a, b}$, Jorge D. Marco ${ }^{d, \dagger}$ \\ and José $\mathrm{F}$. Gil ${ }^{\mathrm{a}, \mathrm{e}, \star \dagger}$
}

\begin{abstract}
Instituto de Investigaciones de Enfermedades Tropicales (IIET), Sede Regional Orán, Facultad de Ciencias de la Salud, Universidad Nacional de Salta. Alvarado 751 - San Ramón de la Nueva Orán-C.P.4530; b Cátedra de Química Biológica y Biología Molecular, Facultad de Ciencias Naturales, Universidad Nacional de Salta. Universidad Nacional de Salta. Av. Bolivia 5150 - CP 4400; 'Parasitology

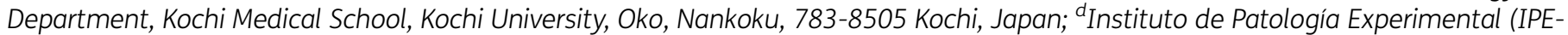
CONICET), Facultad de Ciencias de la Salud, Universidad Nacional de Salta. Av. Bolivia 5150 - CP 4400; Instituto de Investigación en

Energía No Convencional (INENCO-CONICET), Departamento de Física, Universidad Nacional de Salta. Av. Bolivia 5150 - CP 4400
\end{abstract}

*Corresponding author: Tel.: +54-93875803261; E-mail: jgil@conicet.gov.ar

These authors contributed equally to this work.

Received 20 June 2018; revised 17 September 2018; editorial decision 21 September 2018; accepted 21 September 2018

Background: Some sand flies are of medical importance because they are vectors of Leishmania parasites that are responsible for leishmaniasis. The aim of this study was to make a retrospective epidemiological analysis of tegumentary leishmaniasis (TL), to identify Leishmania spp. from patient isolates and to describe the diversity of sand flies from a border area between Bolivia and Argentina.

Methods: TL cases included in the study were diagnosed in an endemic area of the north of Argentina from 1985 to 2017. The parasites isolated were characterized by the cytochrome B method. Sand flies were captured with Centers for Disease Control traps in Aguas Blancas and Media Luna-Algarrobito localities.

Results: A total of 118 cases of TL were analysed. Eight isolates were characterized as Leishmania (Viannia) braziliensis. A total of 1291 sand flies were captured, including Nyssomyia neivai, Cortelezzii complex, Evandromyia sallesi, Migonemyia migonei and Micropygomyia quinquefer. Within the area, sand flies were found in the backyards of houses.

Conclusions: In this region there exists the possibility of peridomestic transmission of TL in the neighbourhoods peripheral to the urban area and in rural environments as well as the risk of transmission to travellers that pass through the customs offices.

Keywords: Argentina, Bolivia, Leishmania (Viannia) braziliensis, sand flies, tegumentary leishmaniasis, travellers

\section{Introduction}

The leishmaniases are a group of protozoan diseases caused by parasites of the genus Leishmania transmitted by dipterous insects commonly known as sand flies (Diptera: Psychodidae: Phlebotominae). Currently the leishmaniases are endemic in 98 countries worldwide with 2 million new cases per year. Further, 350 million people are at risk of infection. ${ }^{1}$ In addition, these protozoan diseases rank among the 10 most important medical problems that affect international travelers. ${ }^{2}$ The spectrum of clinical manifestations includes visceral leishmaniasis (VL) and tegumentary leishmaniasis (TL). The latter form includes simple or multiple cutaneous leishmaniasis (CL), mucocutaneous leishmaniasis (MCL) and diffuse cutaneous leishmaniasis (DCL). ${ }^{3}$

In northern Argentina, Leishmania (Viannia) braziliensis is the most frequently isolated species among patients with $\mathrm{TL}^{4-6}$ although rare cases attributed to Leishmania (Viannia) guyanensis, Leishmania (Viannia) panamensis, ${ }^{7,8}$ and Leishmania (Leishmania) amazonensis have been confirmed. ${ }^{9}$ Visceral leishmaniasis due to Leishmania (Leishmania) infantum has also been reported. ${ }^{10,11}$ Also, Salta province reported the highest number of Argentinian CL cases $(n=69)$ in 2009, with an incidence of $<1$ per 10000 inhabitants. ${ }^{12}$ In Bolivia, in addition to the parasite species referred to above, Leishmania (Viannia)

(c) The Author(s) 2018. Published by Oxford University Press on behalf of Royal Society of Tropical Medicine and Hygiene. All rights reserved. For permissions, please e-mail: journals.permissions@oup.com. 
lainsoni has been described as a causal agent of TL. ${ }^{13}$ In Tarija, between 33 and $37 \mathrm{CL}$ cases were reported, with an incidence of $<1$ per 10000 inhabitants in $2008 .^{12}$ It has been suggested that the transmission cycle of these Leishmania species is zoonotic. $^{14}$

In the northern provinces of Argentina, nine sand fly species have been reported. ${ }^{11,15-17}$ Most studies conducted in Bolivia have focused on the central, eastern and northern regions of that country, but information about sand fly species involved in the transmission and other epidemiological aspects of leishmaniasis in the southern province of Tarija, bordering on Argentina, is incomplete. ${ }^{13,18-20}$

Migration offices located on the border of Bolivia and Argentina, receive hundreds of people from different places around the world who cross the frontier every day. These travellers frequently visit areas located within the ecoregion of Yungas in Bolivia, which overlaps the areas in Argentina that exhibit the highest incidence rates of cases and where the vector has been reported. This shows the higher risk of transmission of leishmaniasis in this border area. ${ }^{5,21-23}$

Thus the aim of the present study was to describe the epidemiological situation of $\mathrm{CL}$ and its temporal variation in an urban area (Aguas Blancas) and rural communities (Media Luna-Algarrobito) in Argentina on the Bolivian frontier. We have also described the spatial distribution and diversity of sand flies in the area. These contributions seek to delimit the areas of high transmission risk of CL and VL. Considering this is a border with immigration and customs offices of both countries, with an international bridge that connects the cities of Aguas Blancas (Argentina) and Bermejo (Bolivia) over the Bermejo River, the movement of tourists and international trade in both directions increases the exposure risk to all those using this border point, highlighting the need for improved surveillance with the ultimate purpose of improving and promoting preventive measures against leishmaniasis for the local population, travellers and temporary visitors.

\section{Materials and methods}

\section{Study area}

The study was performed in the north of Salta province, Argentina, in a border area with Bolivia (Figure 1). The study area, which is part of the Yungas ecoregion, includes the following localities: Aguas Blancas $\left(22^{\circ} 44^{\prime} 0^{\prime} \mathrm{S}, 64^{\circ} 22^{\prime} \mathrm{O}^{\prime} \mathrm{W}\right.$ ), an urban area of 2395 inhabitants of the Oran department separated by the Bermejo River from the city of Bermejo, department of Tarija, Bolivia, and the rural areas of Media Luna $\left(22^{\circ} 41^{\prime} 28.58^{\prime} \mathrm{S}\right.$, $\left.64^{\circ} 15^{\prime} 1.73^{\prime} \mathrm{W}\right)$ and Algarrobito $\left(22^{\circ} 36^{\prime} 46.59^{\prime} \mathrm{S}, 64^{\circ} 14^{\prime} 1.54^{\prime} \mathrm{W}\right)$, with a total of 98 inhabitants, that belongs to the General José de San Martín department.

\section{Study population}

The study population includes cases diagnosed with TL seen at the Instituto de Investigaciones de Enfermedades Tropicales (IIET), Universidad Nacional de Salta, Argentina. The inclusion criteria were patients from Aguas Blancas, Media Luna-Algarrobito or Bolivia diagnosed between 1986 and 2017, with one or more ulcers compatible with $\mathrm{CL}$ or MCL and a positive result for microscopic examination of smears and/or Montenegro skin test (MST). ${ }^{24}$ The whole database was de-identified. The project was evaluated and approved by the Bioethics Committee of the National University of Salta.

The demographic data for Aguas Blancas for the years 1991, 2001 and 2010 were arranged by age and sex and the census radius that includes areas of Media Luna-Algarrobito was obtained from the Dirección de Estadísticas y Censos de la Provincia de Salta. Linear regression was applied in order to estimate the population sizes of the years for which census data were not available.

\section{Diagnostic methods}

The diagnosis of TL was performed at IIET by a combination of methods executed in parallel as previously described. Briefly, Leishmania amastigotes were microscopically identified in smears of dermal scrapings, the MST was applied and analysis of clinical features of the patients was considered. ${ }^{8}$ Diagnosis by microscopy was undertaken, semi-quantitatively classifying each smear according to an increasing amastigote count: $+=$ 1-10 parasites/1000 fields; $++=1-10$ parasites/100 fields; +++ $\geq 10$ parasites $/ 10$ fields and $-=$ no amastigotes $/ 1000$ fields. The MST was applied by intradermally injecting $0.1 \mathrm{~mL}$ of leishmanin ( $40 \mu \mathrm{g}$ of protein $/ \mathrm{mL}$ ) into the forearm for evaluating the induration size after $48 \mathrm{~h}$. Leishmanin was locally prepared with a soluble extract of promastigotes of $L$. (V.) braziliensis, obtained in culture from a patient of our region (strain MHOM/AR/03/ OLO1) as described elsewhere. ${ }^{24}$ Indurations were considered positive if the diameter was $\geq 5 \mathrm{~mm}$. In a previous study by our group, MST performance was analysed retrospectively, highlighting its high sensitivity of $>98 \%$, which is in agreement with previous studies demonstrating a sensitivity of $97.4 \%$ and a specificity of $93.9 \% .^{24,25}$

\section{Molecular identification of Leishmania parasites}

A volume between 0.3 and $0.5 \mathrm{~mL}$ was aspirated from the lesion edges with a syringe with $0.5 \mathrm{~mL}$ of sterile proline balanced salt solution (PBSS) containing $100 \mathrm{U} / \mathrm{mL}$ penicillin and $50 \mu \mathrm{g} / \mathrm{mL}$ streptomycin. The material aspirated was inoculated into Difco blood agar (USMARU) medium containing $20 \%$ of defibrinated rabbit blood. ${ }^{4}$ Positive samples were characterized by cytochrome $b$ gene (cytb) sequencing, slightly modified from Locatelli et al. ${ }^{6}$ Briefly, classic FTA filter paper card fragments of $2 \mathrm{~mm}$ diameter containing culture samples were washed three times for $5 \mathrm{~min}$ with FTA purification reagent (Whatman BioScience, Boston, MA, USA) and twice in $\mathrm{TE}^{-1}$ buffer $(10 \mathrm{mM}$ Tris- $\mathrm{HCl}, 0.1 \mathrm{mM}$ EDTA, $\mathrm{pH}$ 8.0) and then used as a template for the first polymerase chain reaction (PCR). Leishmania spp. were identified by a nested PCR performed with the primers for cytb (modified from Kato et al. ${ }^{26}$ ), L.cyt-ASm (5'-GCGGAGAGRARAG AAAAGGC-3') and L.Cyt-ARm (5'-TGCTAAAAARCCACTCATAAATAT ACTATA-3'), with an initial denaturation at $94^{\circ} \mathrm{C}$ for $15 \mathrm{~min}$ and subsequently 35 cycles of denaturation at $94^{\circ} \mathrm{C}$ for $1 \mathrm{~min}$, annealing at $50^{\circ} \mathrm{C}$ for $1.5 \mathrm{~min}$ and extension at $72^{\circ} \mathrm{C}$ for $1 \mathrm{~min}$, and a final extension phase at $72^{\circ} \mathrm{C}$ for $7 \mathrm{~min}$. From the first PCR 


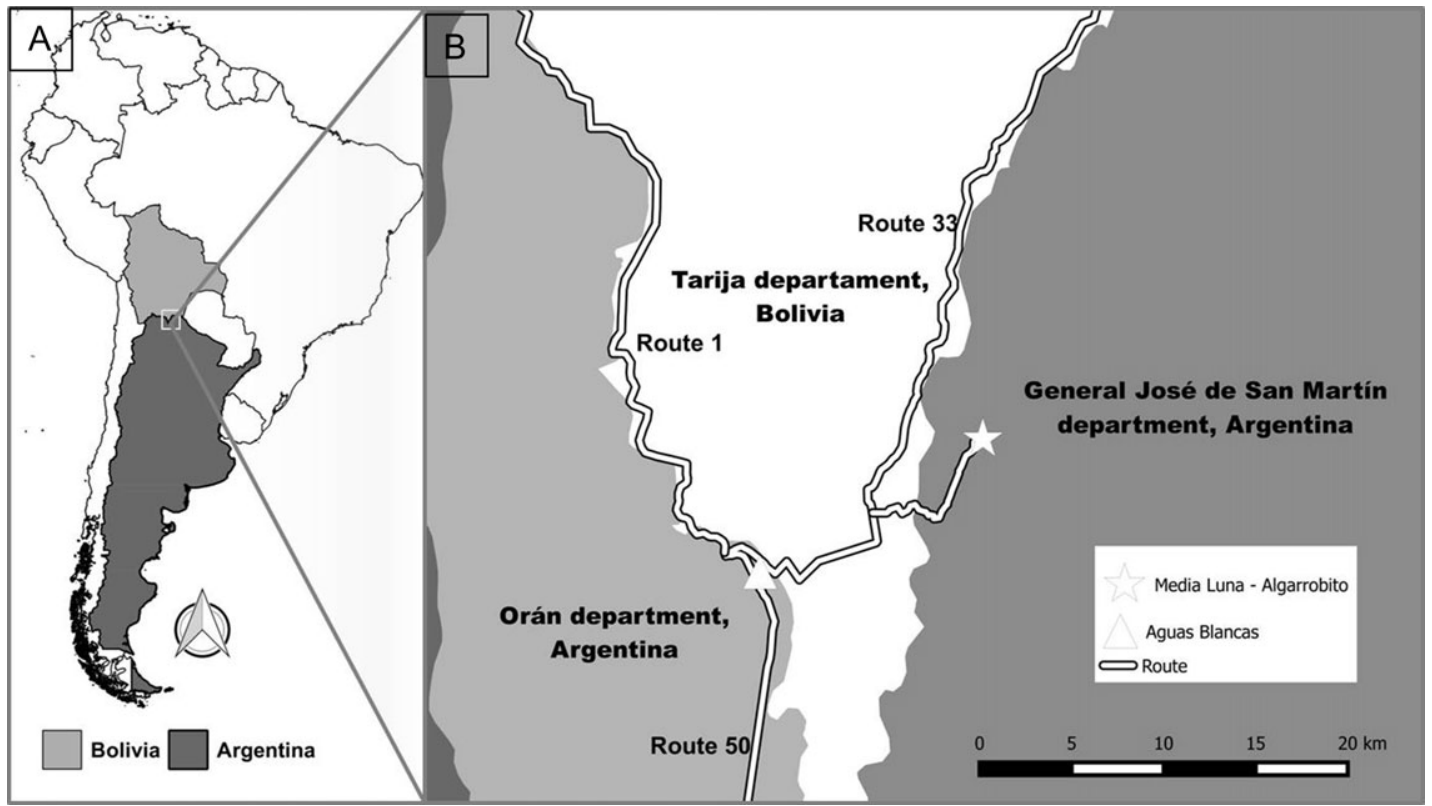

Figure 1. (A) Location of the study area in Latin America. (B) Different sites studied in Oran and General José de San Martín departments in northern Salta (Argentina) and the routes that converge at the Customs office.

solution, $1 \mu \mathrm{l}$ was used as a template for a second PCR by using the primers L.cyt-S (5'-GGTGTAGGTTTTAGTYTAGG-3') and L. cyt-Rm (5'- CTACAATAAACAAATCATAATATRCAATT-3'), performed for 10 min at $94^{\circ} \mathrm{C}$ for initial denaturation, followed by 35 cycles of denaturation at $94^{\circ} \mathrm{C}$ for $1 \mathrm{~min}$, annealing at $55^{\circ} \mathrm{C}$ for $1 \mathrm{~min}$ and a final extension at $72^{\circ} \mathrm{C}$ for $1 \mathrm{~min}$, concluding with a polymerization step at $72^{\circ} \mathrm{C}$ for $7 \mathrm{~min}$. The TaKaRa Ex Taq DNA polymerase hot start version (Takara-Bio, Shiga, Japan) was used in both PCRs. The PCR products were visualized on $1 \%$ agarose gels, then purified and quantified using a NanoDrop-1000 spectrophotometer (NanoDrop Technologies, Wilmington, DE, USA). The amplicons were sequenced using a BigDye terminator cycle sequencing kit, version 1.1 (Applied Biosystems, Foster City, CA, USA), purified in Sephadex G-50 spin columns (Amersham Biosciences, Piscataway, NJ, USA) and analysed on an Applied Biosystems Hitachi 3130 Genetic Analyzer automated sequencer, employing the primers L.cyt-S and L.cyt-Rm. The obtained chromatograms were edited on Chromas Lite version 2.6.5 (Technelysium, South Brisbane, QLD, Australia; https:// technelysium.com.au/wp/chromas/) and aligned by MEGA7 software (https://www.megasoftware.net). ${ }^{27}$ Data were analysed performing a neighbour joining tree with 1000 bootstrap replications using MEGA7 software and compared with the Argentinean strains of $L$. (V.) braziliensis genotypes $A B 1$ and $A B 2$ (gene bank ID for AB1 genotype: MH841941 and for AB2 genotype: MH841942). In addition, The polymorphism-specific PCR (PS-PCR) technique was applied on a sample with negative amplification for cytb sequencing (Table 1$).^{8}$

\section{Entomological study}

Sand flies were captured with Centers for Disease Control light minitraps (John W. Hock Company, Gainesville, FL, USA) located at nine sites in Aguas Blancas and 16 sites in Media Luna-
Table 1. Characterization of parasites isolated from TL patients by age and sex in Aguas Blancas (Salta, Argentina) and Bermejo (Bolivia)

\begin{tabular}{llrll} 
Location & Sex & Age $(y)$ & $\begin{array}{l}\text { cytb } \\
\text { genotype }\end{array}$ & $\begin{array}{l}\text { Clinical } \\
\text { form }\end{array}$ \\
\hline Bermejo, Bolivia & $\mathrm{M}$ & 34 & $\mathrm{AB} 2^{\mathrm{a}}$ & $\mathrm{CL}$ \\
Bermejo, Bolivia & $\mathrm{M}$ & 60 & $\mathrm{ND}$ & $\mathrm{CL}$ \\
Bermejo, Bolivia & $\mathrm{M}$ & 24 & $\mathrm{AB} 1^{\mathrm{b}}$ & $\mathrm{MCL}$ \\
Aguas Blancas, Argentina & $\mathrm{M}$ & 9 & $\mathrm{AB} 1^{\mathrm{b}}$ & $\mathrm{CL}$ \\
Aguas Blancas, Argentina & $\mathrm{M}$ & 40 & $\mathrm{AB} 1^{\mathrm{b}}$ & $\mathrm{CL}$ \\
Aguas Blancas, Argentina & $\mathrm{F}$ & 13 & $\mathrm{AB} 1^{\mathrm{b}}$ & $\mathrm{CL}$ \\
Aguas Blancas, Argentina & $\mathrm{M}$ & 54 & $\mathrm{AB1} 1^{\mathrm{b}}$ & $\mathrm{CL}$ \\
Aguas Blancas, Argentina & $\mathrm{F}$ & 18 & $\mathrm{AB1} 1^{\mathrm{b}}$ & $\mathrm{CL}$
\end{tabular}

ND: not determined by cytb sequencing. Leishmania (V.) braziliensis was identified by PS-PCR.

aSequence identical to gene bank accession number MH841942.

${ }^{b}$ Sequence identical to gene bank accession number MH841941.

Algarrobito from 19:00 to 09:00 the following day. The studied sites' coordinates were registered with eTrex Vista GPS (Garmin, Olathe, KS, USA). In Aguas Blancas, samplings were performed during a total of six nights: three nights in November 2013 and another three nights in February 2015. In Media LunaAlgarrobito the samplings were performed at nine sites in October 2011 (one night of capture) and August 2016 at nine sites (two nights of capture). Only two sites were coincident for both samplings in Media Luna-Algarrobito. 
The morphological analysis for identification of sand fly species consisted of the identification of the following structures of taxonomic value: cibarium and spermathecae (females) and cibarium and external genitalia (males). ${ }^{28,29}$ Females of Evandromyia sallesi and Evandromyia cortelezzii cannot be differentiated by their morphological characteristics so they were classified as Cortelezzii complex.

\section{Statistical analysis}

The TL prevalence was calculated according to age, sex and residence of patients and analysed by means of the $\chi^{2}$ test. The same test was used to compare the frequency of TL cases by age and sex of patients from Bolivia (test of goodness-of-fit adjustment). We used generalized linear models (GLMs) (Poisson link function) to compare the mean sand fly abundance (nighttrap) by geographic area, species, sex and month of capture. The sand fly abundance from the edge and the central sites of the city (Aguas Blancas) were also compared with the same method. All analyses with $p$-values $<0.05$ for a level of significance of $95 \%$ were considered statistically significant. For all statistical analyses, Infostat software version 2016 (Infostat v 2016. Grupo InfoStat, FCA, Universidad Nacional de Córdoba, Argentina. http://www.infostat.com.ar) was used. QGIS 2.10.1 (http://www.qgis.org/es/site/) was used for the drawing of the maps.

\section{Results}

A total of 118 patients who met the case definition for this study were included in the analysis. Most patients were residents of Bolivia (56.78\%), whereas $26.27 \%$ were from Aguas Blancas and $16.95 \%$ from Media Luna-Algarrobito. Regarding the smears, 93 patients were positive, 16 were negative and 9 were not tested. In contrast, by MST, 100 patients were positive, 11 were negative and 7 were not tested. A total of 102 suspected cases of TL were positive according to their smears and/ or MST, of which 75 were positive for both tests, 11 were positive only by smears and 16 were positive only by MST.

Among the cases from Bolivia, 9 (13\%) were MCL and there were peaks in 1997 and 1998 (Figure 2A). The frequency of males $(68 \%, p<0.05)$ was significantly higher than that observed for of females. The age range with the greatest number of $C L$ cases was from 15 to 64 years old $(p<0.0001)$.

In Aguas Blancas, 31 cases of $\mathrm{CL}$ have been diagnosed since 1998. Between 1998 and 2014, the prevalence per year was $\leq 0.16 \%$. In 2015 a peak of cases was registered, with an observed prevalence of $0.46 \%$, which was followed by a decrease to $0.17 \%$ (Figure 2B). The observed prevalence in males was higher than in females $(2.45 \%$ and $0.84 \%$, respectively; $p<0.05$ ). The prevalence by age was $0.95 \%$ for children $<15$ years and $1.82 \%$ for adults, and no statistically significant differences were observed between them ( $p=0.176)$.

In Media Luna-Algarrobito, TL cases have been diagnosed since 1997. The prevalence per year did not exceed 3.09\%, except in 2002 when the registered prevalence was 14.25\% (Figure 2C). Of the 20 cases diagnosed in these rural areas, 1 was diagnosed as MCL. Among adults, the male prevalence
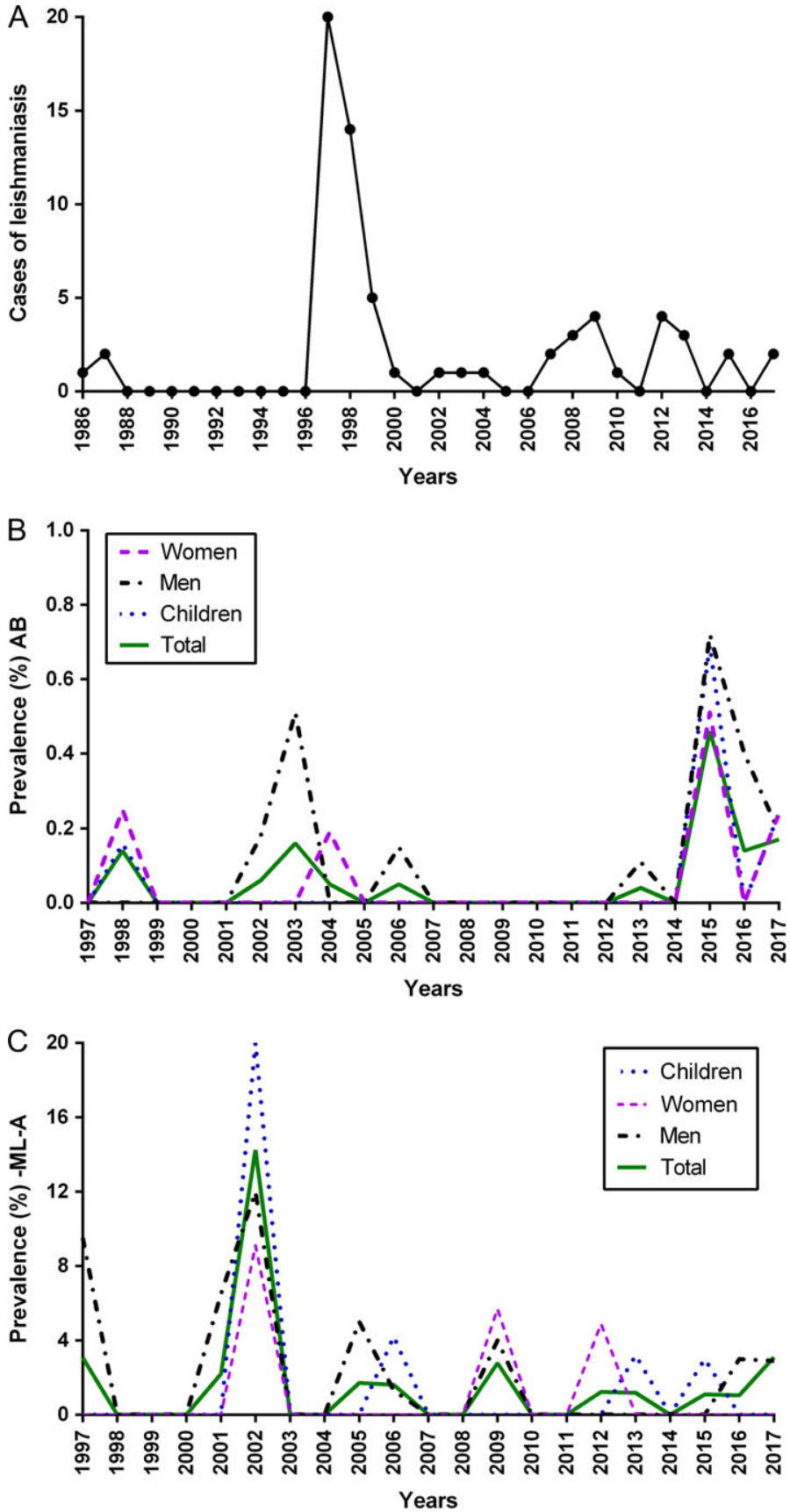

Figure 2. (A) Number of cases of leishmaniasis from Bolivian patients diagnosed at the IIET and reported per year from 1986 to 2017. (B) Prevalence of TL in Aguas Blancas per year from 1997 to 2017. (C) Prevalence of TL in Media Luna-Algarrobito per year from 1997 to 2017.

$(38.89 \%)$ was significantly higher than that observed in women $(17.24 \%, p<0.05)$. The prevalence by age group was $26.92 \%$ for children, while for adults it was $30.77 \%$, with no significant statistical differences $(p=0.738)$.

For the comparison of overall prevalence of TL between the two study areas, only the cases between 1997 and 2017 were considered, because it is in that period that TL cases were registered in both study areas. In Aguas Blancas, an overall prevalence 
of $1.62 \%$ was observed, significantly lower than in Media LunaAlgarrobito, where the prevalence was $29.23 \%$ ( $p<0.0001)$. In subgroup analysis, this difference in prevalence continued to be significant when analysed by sex and age.

Three parasites from Bolivia and five from Aguas Blancas were successfully isolated and identified as L. (V.) braziliensis. Six of these parasites corresponded to the Ab-1 sequence of the cytb gene and one was isolated to the Ab-2 sequence (Table 1).

A total of 1291 sand flies were collected: 374 in Aguas Blancas and 917 in Media Luna-Algarrobito. The last locality presented a higher average of sand flies per night-trap $(n=5.26)$, whereas Aguas Blancas was fewest $(n=1.45)$, with statistically significant differences $(p<0.05)$. The average number of sand flies for Aguas Blancas was 1.67 Nyssomyia neivai per nighttrap, 2 Cortelezzii complex, 1.72 Ev. sallesi and 0.58 Migonemyia migonei. The average for $\mathrm{Mg}$. migonei showed statistical differences with the other species $(p<0.05)$. The mean of Micropygomyia quinquefer was not calculated because this species was found in only one sampled site. The average number of sand flies for Media Luna-Algarrobito was $19.06 \mathrm{Ny}$. neivai per night-trap, $1.47 \mathrm{Mg}$. migonei, 0.06 Cortelezzii complex and 0.11 Ev. sallesi. Nyssomyia neivai $(p<0.001)$ and Mg. migonei $(p<0.05)$ showed significant differences with the other species, while Cortelezzii complex and Ev. sallesi did not ( $p>0.05)$. Overall, $1.9 \%$ of the captured sand flies could not be identified at the species level due to taxonomic structure losses during processing.
When we compared female means we found that in Aguas Blancas there were no significant differences between species (Ny. neivai: 1.77; Mg. migonei: 0.98; Cortelezzii complex: 0.39). Meanwhile, in Media Luna-Algarrobito, Ny. neivai showed a higher average $(15.62 ; \mathrm{p}<0.0001)$ than $\mathrm{Mg}$. migonei $(0.45)$ and Cortelezzii complex (0.06) and these last two species showed no significant differences between them ( $p>0.05)$.

In Aguas Blancas, sand flies were captured at eight of the nine sites, with the highest frequency of captures occurring on the edges of the city $(p<0.0001)$ (Figure 3$)$. Nyssomyia neivai was present at six of nine sampling sites, but it was not captured at the sites in the centre of the city (sites 1,7 and 8). Cortelezzii complex and Ev. sallesi were captured at seven sampling sites (2, 3, 4, 5, 6, 7 and 9) and Mg. migonei at eight sampling sites. Table 2 shows the abundance of sand flies per night-trap by sex and site. Male sand flies were found at statistically higher averages than females $(p<0.0001)$.

In Aguas Blancas, the total abundance of sand flies captured during November 2013 was higher than that in February 2015 $(p<0.0001)$. Regarding the abundance of Ny. neivai by sampling month, a lower abundance was observed in November 2013 (1.44 sand flies per night-trap) compared with February 2015 (1.89 sand flies per night-trap) without statistically significant differences ( $p>0.05$ ). However, Cortelezzii complex (including Ev. sallesi) showed a greater abundance in the first sampling (7.50 sand flies per night-trap) than the second $(0.60, p<0.0001)$. The average number of $\mathrm{Mg}$. migonei also demonstrated significant

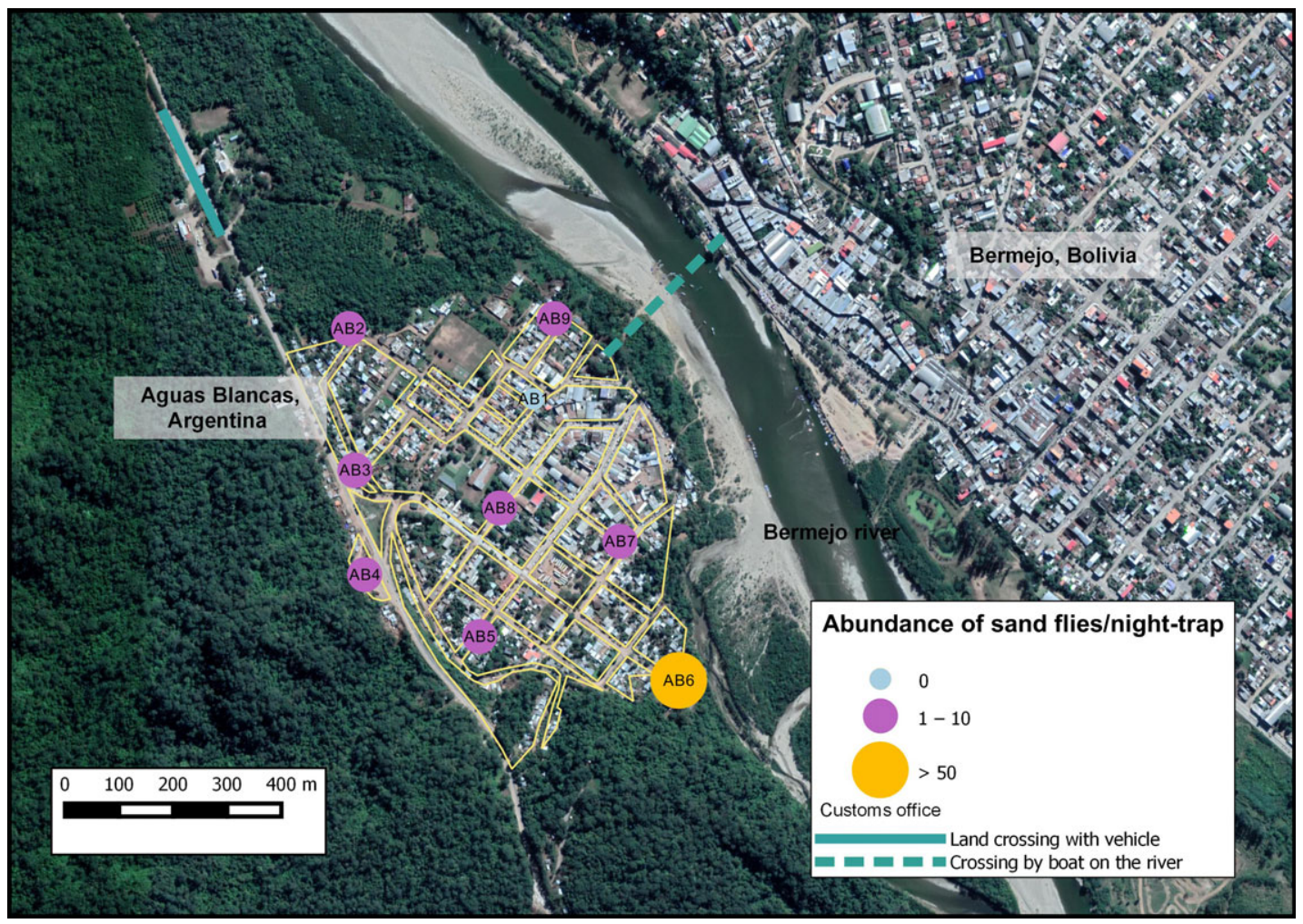

Figure 3. Abundance of sand flies by site on the day of capture in Aguas Blancas. The continuous line represents the Customs office and the place where vehicles line up to cross from one country to another on route 50, which is surrounded by primary vegetation. The dashed line represents the circuit that people use to cross by boat from one country to another. The Customs office is located on the Argentina side (next to site AB9) and is surrounded by wild vegetation. 
Table 2. Abundance of sand flies by sex per site per night-trap in Aguas Blancas and Media Luna-Algarrobito

\begin{tabular}{|c|c|c|c|c|c|c|c|c|c|c|c|}
\hline \multirow[t]{2}{*}{ Site } & \multirow{2}{*}{$\begin{array}{l}\text { Cortelezzii complex } \\
\text { F }\end{array}$} & \multirow{2}{*}{$\begin{array}{l}\text { Ev. sallesi } \\
\text { M }\end{array}$} & \multicolumn{2}{|c|}{ Mg. migonei } & \multicolumn{2}{|c|}{ Ny. neivai } & \multicolumn{2}{|c|}{$\begin{array}{l}\text { Mi. } \\
\text { quinquefer }\end{array}$} & \multicolumn{2}{|c|}{$\begin{array}{l}\text { Lutzomyia } \\
\text { spp. }\end{array}$} & \multirow[t]{2}{*}{ Total per site } \\
\hline & & & $\mathrm{F}$ & M & $\mathrm{F}$ & M & $\mathrm{F}$ & M & $\mathrm{F}$ & $\mathrm{F}$ & \\
\hline AB1 & 0.00 & 0.00 & 0.00 & 0.00 & 0.00 & 0.00 & 0.00 & 0.00 & 0.00 & 0.00 & 0.00 \\
\hline AB2 & 2.00 & 2.40 & 1.00 & 2.00 & 0.60 & 0.60 & 0.00 & 0.00 & 0.00 & 0.00 & 8.60 \\
\hline AB3 & 1.33 & 0.67 & 0.17 & 0.00 & 0.33 & 0.33 & 0.00 & 0.00 & 0.00 & 0.00 & 2.83 \\
\hline AB4 & 0.17 & 0.50 & 0.00 & 0.17 & 0.33 & 2.17 & 0.00 & 0.00 & 0.00 & 0.00 & 3.33 \\
\hline AB5 & 0.33 & 0.00 & 0.00 & 0.50 & 0.17 & 1.17 & 0.00 & 0.00 & 0.00 & 0.33 & 2.50 \\
\hline AB6 & 11.40 & 8.40 & 3.20 & 3.00 & 8.40 & 16.20 & 0.00 & 0.00 & 0.40 & 0.80 & 51.80 \\
\hline$A B 7$ & 0.50 & 0.17 & 0.17 & 0.17 & 0.00 & 0.00 & 0.00 & 0.17 & 0.00 & 0.00 & 1.17 \\
\hline AB8 & 0.00 & 0.00 & 0.00 & 0.17 & 0.00 & 0.00 & 0.00 & 0.00 & 0.00 & 0.00 & 0.17 \\
\hline AB9 & 0.33 & 0.83 & 0.00 & 0.33 & 0.00 & 0.33 & 0.17 & 0.00 & 0.00 & 0.00 & 2.00 \\
\hline$M L-A 1^{a}$ & 0.33 & 0.67 & 2.67 & 15.33 & 63.67 & 126.00 & 0.00 & 0.00 & 1.67 & 3.00 & 213.33 \\
\hline$M L-A 2^{C}$ & 0.00 & 0.00 & 0.00 & 0.00 & 0.00 & 0.00 & 0.00 & 0.00 & 0.00 & 0.00 & 0.00 \\
\hline$M L-A 3^{C}$ & 0.00 & 0.00 & 0.00 & 0.00 & 0.00 & 0.00 & 0.00 & 0.00 & 0.00 & 0.00 & 0.00 \\
\hline$M L-A 4^{b}$ & 0.00 & 0.00 & 0.00 & 0.00 & 20.00 & 7.50 & 0.00 & 0.00 & 0.00 & 0.00 & 27.50 \\
\hline$M L-A 5^{C}$ & 0.00 & 0.00 & 0.00 & 0.00 & 0.00 & 1.00 & 0.00 & 0.00 & 0.00 & 0.00 & 1.00 \\
\hline$M L-A \sigma^{C}$ & 0.00 & 0.00 & 0.00 & 0.00 & 3.50 & 0.50 & 0.00 & 0.00 & 0.00 & 0.00 & 4.00 \\
\hline$M L-A 7^{C}$ & 0.00 & 0.00 & 0.00 & 0.00 & 0.00 & 0.37 & 0.00 & 0.00 & 0.37 & 0.37 & 1.11 \\
\hline$M L-A 8^{a}$ & 0.00 & 0.00 & 0.00 & 0.00 & 35.67 & 12.67 & 0.00 & 0.00 & 0.33 & 0.00 & 48.67 \\
\hline$M L-A 9^{C}$ & 0.00 & 0.00 & 0.00 & 0.00 & 0.00 & 1.00 & 0.00 & 0.00 & 0.00 & 0.00 & 1.00 \\
\hline ML-A10 & 0.00 & 0.00 & 0.00 & 0.00 & 2.50 & 0.00 & 0.00 & 0.00 & 0.00 & 0.00 & 2.50 \\
\hline$M L-A 11^{b}$ & 0.00 & 0.00 & 0.00 & 0.00 & 5.50 & 4.00 & 0.00 & 0.00 & 0.00 & 0.00 & 9.50 \\
\hline$M L-A 12^{b}$ & 0.00 & 0.00 & 0.00 & 0.00 & 0.50 & 1.00 & 0.00 & 0.00 & 0.00 & 0.00 & 1.50 \\
\hline$M L-A 13^{b}$ & 0.00 & 0.00 & 0.00 & 0.00 & 6.00 & 0.00 & 0.00 & 0.00 & 0.00 & 0.00 & 6.00 \\
\hline$M L-A 14^{b}$ & 0.00 & 0.00 & 0.00 & 0.00 & 6.00 & 0.50 & 0.00 & 0.00 & 0.00 & 0.00 & 6.50 \\
\hline$M L-A 15^{C}$ & 0.00 & 0.00 & 0.00 & 0.00 & 6.00 & 2.00 & 0.00 & 0.00 & 0.00 & 0.00 & 8.00 \\
\hline$M L-A 16^{C}$ & 0.00 & 0.00 & 0.00 & 0.00 & 2.00 & 1.00 & 0.00 & 0.00 & 0.00 & 0.00 & 3.00 \\
\hline Total AB & 16.07 & 12.97 & 4.53 & 6.33 & 9.83 & 20.80 & 0.17 & 0.17 & 0.40 & 1.13 & 72.40 \\
\hline Total ML-A & 0.33 & 0.67 & 2.67 & 15.33 & 151.33 & 157.54 & 0.00 & 0.00 & 2.37 & 3.37 & 333.61 \\
\hline
\end{tabular}

variation between sampling months (November 0.94, February $0.22 ; p<0.01)$.

In Media Luna-Algarrobito, sand flies were captured at 14 of the 16 sampling sites. Sampling site 1 had the highest abundance of sand flies per night-trap $(n=213.33)$ (Figure 4), with Ny. neivai being the predominant species $(n=189.66)$, followed by site $8(n=48.33)$. Nyssomyia neivai was captured at all the positive sampling sites. Cortelezzii complex, Ev. sallesi and Mg. migonei were present only at site 1 . Table 2 shows the abundance of sand fly species per night-trap by sex and site. Regarding the abundance of $\mathrm{Ny}$. neivai by sampling month, a greater abundance was observed in October 2011 (37.06 sand flies per night-trap) compared with August 2016 (7.09 sand flies per night-trap), with statistically significant differences $(p<0.0001)$. The abundance of $\mathrm{Mg}$. migonei was higher in October 2011
(3.79 sand flies per night-trap) than August 2016, when only one specimen was captured at site 1 .

Of the total sand flies for both study areas, the highest mean was observed in October 2011, followed by August 2016, November 2013 and February 2015, with statistically significant differences between all months $(p<0.0001)$ (Table 3$)$. This observation coincides with the comparison of mean female sand flies by month and study area.

\section{Discussion}

The demographic phenomena of migration and short-stay dispersion are important from an epidemiological point of view and are of interest for national and international public health 


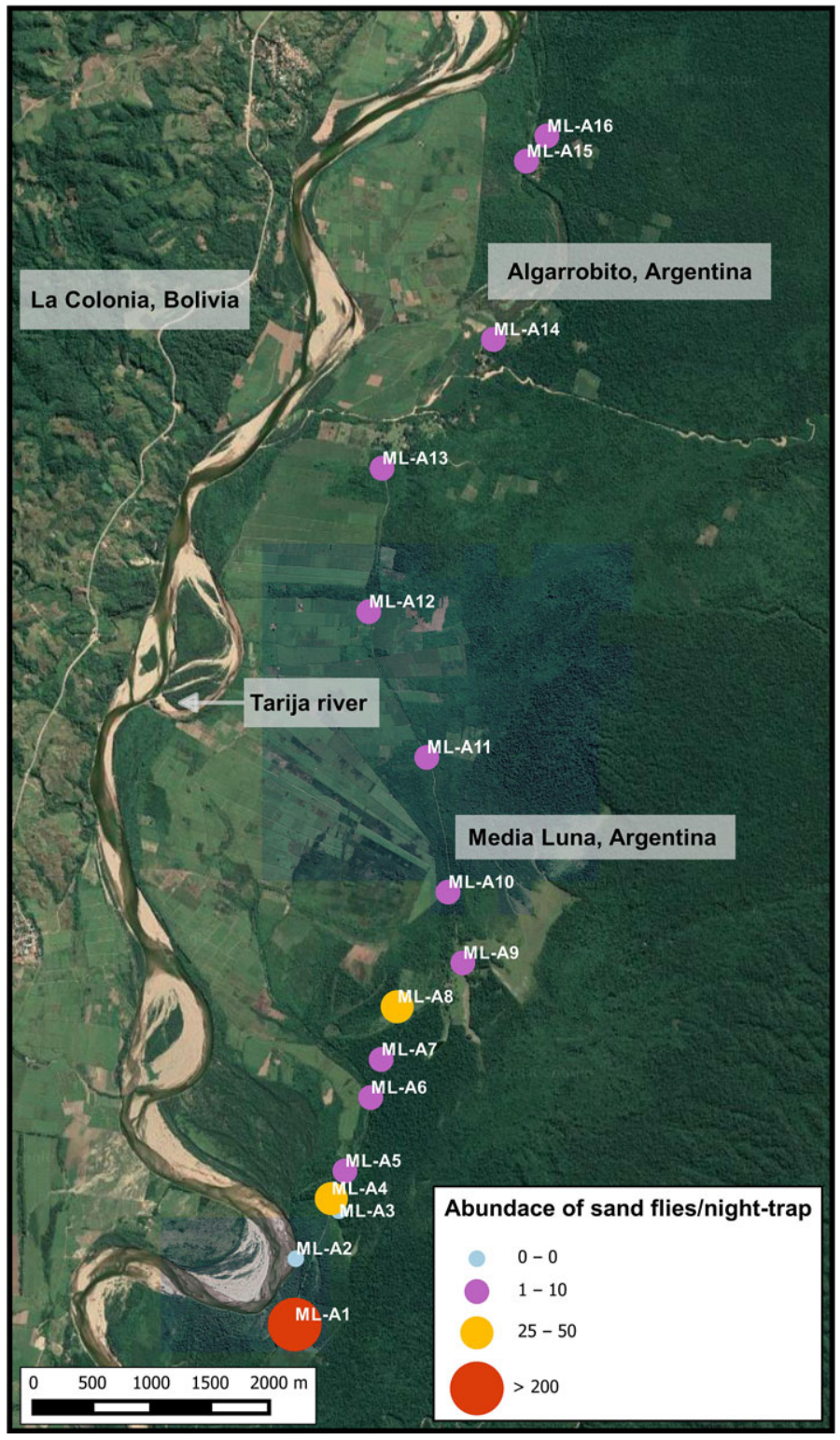

Figure 4. Abundance of sand flies by site on the day of capture in Media Luna-Algarrobito. The landscape combines small crops with wild vegetation. The ML-A1 site corresponds to a house with a barn with abundant organic matter in the soil.

systems. Travellers that come from countries where leishmaniasis is not endemic have been infected by Leishmania parasites after traveling to countries such as Bolivia, Brazil and Argentina. ${ }^{2,30}$ These studies suggest that international borders can provide favourable scenarios for the transmission and dissemination of various diseases due to the large number and great concentration of susceptible people that may be exposed to the vectors.

We detected genotypes $A B 1$ and $A B 2$ of $L$. (V.) braziliensis in $\mathrm{CL}$ cases from both sides of the Argentina-Bolivia border. This is in agreement with previous studies carried out in the Oran department, Salta province, where the same L. (V.) braziliensis genotypes were isolated and characterized from ulcers of patients
Table 3. Average of sand flies captured per sampling month in Media Luna-Algarrobito and Aguas Blancas

\begin{tabular}{llcl} 
Month & Study area & Mean & SE \\
\hline October 2011 & Media Luna-Algarrobito & 13.95 & 0.58 \\
August 2016 & Media Luna-Algarrobito & 2.36 & 0.19 \\
November 2013 & Aguas Blancas & 1.46 & 0.14 \\
February 2015 & Aguas Blancas & 0.6 & 0.09
\end{tabular}

All means had a significant difference $(p<0.05)$. SE: Standard error.

with $\mathrm{CL}$ and MCL., ${ }^{4,6}$ However, there are no published studies reporting which Leishmania species circulate in areas of the Tarija department (Bolivia), which borders on Argentina. Although cases of $\mathrm{CL}$ caused by $\mathrm{L}$. (L.) amazonensis were detected in Argentina, ${ }^{9}$ no DCL cases or its vectors Bichromomyia flaviscutellata or Lutzomyia nuneztovari anglesi have been reported, suggesting that those cases were imported rather than locally acquired. In addition, regarding VL, which is endemic in some departments of central and northern Bolivia, Mg. migonei and Mi. quinquefer have been associated with $L$. (L.) infantum transmission, which has been found in this bordering area. This situation implies the need for surveillance in order to prevent outbreaks or the establishment of $\mathrm{VL}$ in the region. ${ }^{11,31}$ Also, other risk factors, such as the international transport of dogs, could play an important role in the establishment of $\mathrm{VL}$ in the region, and especially in northwest Argentina.

Seasonal labour-related activities in agriculture and lumber production are the main reasons for migrants from Bolivia to move to small cities of northern Argentina. This situation is reflected in the fact that most of the Bolivian patients that were diagnosed with TL were men of working age. We suggest that many of these cases were infected in rural, wild or deforested areas in Oran (Argentina), 5,21,32 although we cannot rule out the possibility that some patients might have been infected in their country of origin. In addition, the highest number of registered Bolivian patients in the period of our study coincides with the outbreak that occurred in 1997-1998 (Figure 2A) north of Salta province, related with deforestation activities. ${ }^{12,32,33}$ In the Tarija department, the presence of $\mathrm{Ny}$. neivai and an outbreak of $\mathrm{CL}$ in Bermejo have been reported. ${ }^{19,20}$ Dujardin et al. ${ }^{18}$ reported Mi. quinquefer in Tarija and we also identified this species in the study areas, suggesting the existence of an ecological continuity for these sand fly species.

In contrast, large numbers of people from different places in Argentina, Bolivia and other countries arrive daily in Aguas Blancas by bus and private transport. This constant geographic funnel (Figures 1B and 3) could generate an important scenario for exposing numerous susceptible people to leishmaniasis. Thus it is possible that a certain number of cases reported in other nearby cities of Salta province (Orán or Tartagal), in other provinces of Argentina and Bolivia and in other countries might have occurred by virtue of exposure to vectors in this border area. $^{30}$

Considering the impact on the local population, the presence of $\mathrm{Ny}$. neivai, Mg. migonei and the Cortelezzii complex in the 
neighbourhoods of Aguas Blancas may be an indication of the risk for domestic or peridomestic transmission in this area (Figure 3). This is consistent with the increasing urbanization and domiciliation of leishmaniasis vectors. ${ }^{23,34,35}$ It is important to note that most of the cases that contributed to the prevalence peaks of 2015 and 2017 in Aguas Blancas came from a new settlement located on the southern edge of the city near site AB6 (Table 2, Figures 2B and 3).

All the captured sand fly species from Aguas Blancas and Media Luna-Algarrobito are suspected of transmitting some species of the genus Leishmania. Nyssomyia neivai, Mg. migonei and Cortelezzii complex were found to be naturally infected by different species of Leishmania in several areas of Argentina and other Latin America countries. In addition, the anthropophilia of these sand fly species has also been described. ${ }^{36-41}$

Previous studies suggest that in northern Argentina, the possible periods of the year with the highest risk of transmission are summer-autumn and spring-summer, with peaks of bimodal or trimodal abundances, all associated with temperatures and precipitation with a particular temporal lag. ${ }^{17}$ In agreement with this study, in Media Luna-Algarrobito we found greater sand fly abundance in October compared with August. Likewise for Aguas Blancas, the abundance in November was significantly greater than in February, which results in a seasonal variation of the transmission risk that must be considered when planning preventive and control measures.

We also observed interannual peaks of $T L$ prevalence in Aguas Blancas and Media Luna-Algarrobito at intervals of 3-4 y (Figures 2B and C). This observation has been reported in other studies showing cycles in the incidence of leishmaniasis of 3-4 y associated with changes in temperature and El Niño Southern Oscillation indices. ${ }^{42}$ In Aguas Blancas, between 2007 and 2012 there were no cases of TL reported. This could be related to vector control activities by the local public health system for malaria control (Figure 2B).

The higher prevalence of $\mathrm{CL}$ in Media Luna-Algarrobito than in Aguas Blancas can be explained by the locations of the houses, which combines family agriculture with moderately preserved and dense wild vegetation. ${ }^{43}$ Sand flies were more abundant in this rural area than in Aguas Blancas. Sampling sites 1 and 8 exhibited the greatest sand fly abundance (Figure 4). These insects can easily access the peridomiciliary (and the intradomiciliary) environment in almost all the houses. ${ }^{21}$ Therefore the risk of transmission of leishmaniasis will depend on the distance from the house to an infected wild reservoir. In fact, the absence of significant differences by age group may suggest home and/or peridomiciliary exposure in Aguas Blancas and Media Luna-Algarrobito. ${ }^{21-23,35}$

The under or overestimation of population sizes by linear regression represents a limitation of the present study. However, we consider that its purpose in seeking to demonstrate the occurrence of leishmaniasis cases and its maintenance over time does not affect our conclusions. Regarding entomological surveys, it is necessary to carry out prospective studies in order to confirm that less frequent sand fly species may be present in the study area but were undetected due to the limited capture effort.

Epidemiological patterns of transmission may be involved in the ecological scenarios of this border area between Bolivia and Argentina and might include peridomestic transmission in the rural area as well as in the peri-urban area (Figures 3 and 4). Currently, prevention and control programs for leishmaniasis do not cover these scenarios, a fact that should be re-evaluated. For example, the use of mosquito nets and the implementation of entomological monitoring and fumigation over areas of risk, as well as the weeding of peridomiciliary areas might have a positive impact in the current epidemiological situation. Many of the cases of patients from Bolivia may be due to agricultural, logging and/or recreational activities (hunting, fishing, etc.). Prevention policies should include health education on leishmaniasis in schools, the use of digital media to educate individuals on personal protection measures and measures to avoid exposing workers. The geographic funnel at border crossings can represent an important risk factor for travellers while they wait to complete their immigration and customs procedures (at times for hours) in areas that serve as a refuge for sand flies (Figure 3).

\section{Conclusions}

The majority of sand fly species reported in our study are suspected of transmitting parasites that cause leishmaniasis. The abundance of sand flies is higher in the rural area. Also, in the urban area, the highest number of sand flies is found at the margins of the city of Aguas Blancas. Nyssomyia neivai is the most prevalent species, being present in all the sites where sand flies were caught. In addition, L. (V.) braziliensis is endemic in the south of Bolivia and in the north of Argentina. With control measures being insufficient if carried out just by a single country at a border area, we propose further studies in border areas to provide the knowledge necessary to determine integrated international prevention measures.

Authors' contributions: JFG, GNC, AJK and NRJ contributed to the study design, data collection, data analysis, literature search and writing of the manuscript. MCA, LVA, SPC, MJ, JJL, MK, PB and JDM contributed to the processing of samples and writing of the manuscript. All authors read and approved the final manuscript.

Acknowledgments: We thank the staff of Dirección General de Estadísticas de la Provincia de Salta for population information and the staff of Instituto de Investigación de Enfermedades Tropicales for collaboration in the collection and processing of samples. JFG and AJK are career members of Consejo Nacional de Investigaciones Científicas y Técnicas (CONICET) and GNC and MCA are doctorate scholars from the same institution.

Funding: This study was supported in part by the Consejo de Investigación de la Universidad Nacional de Salta (CIUNSa; 2256, 2356) and Fondo para la Investigación Científica y Tecnológica (FONCYT) Proyectos de Investigación Científica y Tecnológica (PICT) 2009 (0135), FONCYT PICT 2013 (3213) and FONCYT PICT 2014 (1579).

Competing interests: None declared.

Ethical approval: Not required. 


\section{References}

1 Karimkhani C, Wanga V, Coffeng LE, et al. Global burden of cutaneous leishmaniasis: a cross-sectional analysis from the Global Burden of Disease Study 2013. Lancet Infect Dis. 2016;16(5):584-91.

2 Pavli A, Maltezou HC. Leishmaniasis, an emerging infection in travelers. Int J Infect Dis. 2010;14(12):e1032-9.

3 Herwaldt BL. Leishmaniasis. Lancet. 1999;354(9185):1191-9.

4 Marco JD, Barroso PA, Calvopiña M, et al. Species assignation of Leishmania from human and canine American tegumentary leishmaniasis cases by multilocus enzyme electrophoresis in north Argentina. Am J Trop Med Hyg. 2005;72(5):606-11.

5 Krolewiecki AJ, Gil JF, Quipildor M, et al. Restricted outbreak of American tegumentary leishmaniasis with high microfocal transmission. Am J Trop Med Hyg. 2013;88(3):578-82.

6 Locatelli FM, Cajal SP, Barroso PA, et al. The isolation and molecular characterization of Leishmania spp. from patients with American tegumentary leishmaniasis in northwest Argentina. Acta Trop. 2014; 131:16-21.

7 Marco JD, Uezato H, Mimori T, et al. Are cytochrome B gene sequencing and polymorphism-specific polymerase chain reaction as reliable as multilocus enzyme electrophoresis for identifying Leishmania spp. from Argentina? Am J Trop Med Hyg. 2006;75(2):256-60.

8 Marco JD, Barroso PA, Mimori T, et al. Polymorphism-specific PCR enhances the diagnostic performance of American tegumentary leishmaniasis and allows the rapid identification of Leishmania species from Argentina. BMC Infect Dis. 2012;12:191.

9 Frank FM, Fernández MM, Taranto NJ, et al. Characterization of human infection by Leishmania spp. in the northwest of Argentina: immune response, double infection with Trypanosoma cruzi and species of Leishmania involveds. Parasitology. 2003;126(Pt 1): 31-9.

10 Barrio A, Parodi CM, Locatelli F, et al. Leishmania infantum and human visceral leishmaniasis, Argentina. Emerg Infect Dis. 2012;18 (2):354-5.

11 Barroso PA, Marco JD, Locatelli FM, et al. Visceral leishmaniasis caused by Leishmania infantum in Salta, Argentina: possible reservoirs and vectors. Am J Trop Med Hyg. 2015;93(2):334-9.

12 Alvar J, Vélez ID, Bern C, et al. Leishmaniasis worldwide and global estimates of its incidence. PLoS One. 2012;7(5):e35671.

13 Garcia AL, Parrado R, Rojas E, et al. Leishmaniases in Bolivia: comprehensive review and current status. Am J Trop Med Hyg. 2009;80(5): 704-11.

14 Desjeux P. Worldwide increasing risk factors for leishmaniasis. Med Microbiol Inmunol. 2001;190(1-2):77-9.

15 Bravo AG, Quintana MG, Abril M, et al. The first record of Lutzomyia longipalpis in the Argentine northwest. Mem Inst Oswaldo Cruz. 2013;108(8):1071-3.

16 Quintana MG, Salomón OD, De Grosso MSL. Distribution of phlebotomine sand flies (Diptera: Psychodidae) in a primary forest-crop interface, Salta, Argentina. J Med Entomol. 2010;47(6):1003-10.

17 Salomón OD, Wilson ML, Munstermann LE, et al. Spatial and temporal patterns of phlebotomine sand flies (Diptera: Psychodidae) in a cutaneous leishmaniasis focus in northern Argentina. J Med Entomol. 2004;41(1):33-9.

18 Dujardin JP, Le Pont F, Martinez E. Quantitative morphological evidence for incipient species within Lutzomyia quinquefer (Diptera: Psychodidae). Mem Inst Oswaldo Cruz. 1999;94(6):829-36.

19 Marcondes CB, Le Pont F, Lozovei AL. Lutzomyia neivai (Pinto) in Bolivia (Diptera, Psychodidae, Phlebotminae). Med Inst Oswaldo Cruz. 1998;93(2):203-4.
20 Mollinedo S, Torrez M, Le Pont F. Re-emergencia de la leishmaniasis en Tarija, Frontera con la Argentina. Instituto Nacional de Laboratorios de Salud. Informe Técnico. 2000;7:1-2.

21 Salomón OD, Sosa Estani S, Canini L, et al. [Tegumentary leishmaniasis in area with epidemic levels of transmission, Salta, Argentina, 1998]. Medicina (B Aires). 2001;61(3):284-90.

22 Hoyos CL, Cajal SP, Juarez M, et al. Epidemiology of American tegumentary leishmaniasis and Trypanosoma cruzi infection in the northwestern Argentina. Biomed Res Int. 2016;2016:6456031.

23 Chanampa M del M, Gleiser RM, et al. Vegetation cover and microspatial distribution of sand flies (Diptera: Psychodidae) in an endemic locality for cutaneous leishmaniasis in northern Argentina. J Med Entomol. 2018. https://doi.org/10.1093/jme/tjy129.

24 Krolewiecki AJ, Almazan MC, Quipildor M, et al. Reappraisal of Leishmanin Skin Test (LST) in the management of American cutaneous leishmaniasis: a retrospective analysis from a reference center in Argentina. PLoS Negl Trop Dis. 2017;11(10):e0005980.

25 Skraba CM, de Mello TFP, Pedroso RB, et al. Evaluation of the reference value for the Montenegro skin test. Rev Soc Bras Med Trop. 2015;48(4):437-44.

26 Kato H, Cáceres AG, Mimori T, et al. Use of FTA cards for direct sampling of patients' lesions in the ecological study of cutaneous leishmaniasis. J Clin Microbiol. 2010;48(10):3661-5.

27 Kumar S, Stecher G, Tamura K. MEGA7: Molecular Evolutionary Genetics Analysis version 7.0 for bigger datasets. Mol Biol Evol. 2016; 33(7):1870-4.

28 Young DG, Duncan MA. Guide to the identification and geographic distribution of Lutzomyia sand flies in Mexico, the west Indies, central and south America (Diptera: Psychodidae). Memoirs of the American Entomological Institute no. 54. Gainesville, FL: American Entomological Institute, 1994; p. 54-81.

29 Galati E. Classificação de Phlebotominae. Flebotomíneos do Brasil. In Rangel E, Lainson R (editors). Fiocruz: Rio do Janeiro, 2003, pp. 23-51.

30 Lawn SD, Whetham J, Chiodini PL, et al. New world mucosal and cutaneous leishmaniasis: an emerging health problem among British travellers. QJM. 2004;97(12):781-8.

31 Moya SL, Giuliani MG, Santini MS, et al. Leishmania infantum DNA detected in phlebotomine species from Puerto Iguazú City, Misiones province, Argentina. Acta Trop. 2017;172:122-4.

32 Sosa-Estani S, Segura EL, Gomez A, et al. [Cutaneous leishmaniasis in Northern Argentina: identification of risk factors in a case-cohort study of three municipalities in Salta]. Rev Soc Bras Med Trop. 2001; 34(6):511-7.

33 Salomón OD, Quintana MG, Rosa JR. Ecoepidemiologia de la leishmaniasis cutanea en la Argentina. Soc Iberoam Inf Cient. 2008;16:514-20.

34 Campbell-Lendrum D, Dujardin JP, Martinez E, et al. Domestic and peridomestic transmission of American cutaneous leishmaniasis: changing epidemiological patterns present new control opportunities. Mem Inst Oswaldo Cruz. 2001;96(2):159-62.

35 Gil JF, Nasser JR, Cajal SP, et al. Urban transmission of American cutaneous leishmaniasis in Argentina: spatial analysis study. Am J Trop Med Hyg. 2010;82(3):433-40.

36 Pita-pereira D, Souza GD, Zwetsch A, et al. First report of Lutzomyia (Nyssomyia) neivai (Diptera: Psychodidae: Phlebotominae) naturally infected by Leishmania (Viannia) braziliensis in a periurban area of south Brazil using a multiplex polymerase chain reaction assay. Am J Trop Med Hyg. 2009;80(4):593-5.

37 Rosa J, Pereira DP, Brazil RP, et al. Natural infection of cortelezzii complex (Diptera: Psychodidae: Phlebotominae) with Leishmania braziliensis in Chaco, Argentina. Acta Trop. 2012;123(2):128-31. 


\section{G. N. Copa et al.}

38 Moya SL, Giuliani MG, Manteca Acosta M, et al. First description of Migonemyia migonei (França) and Nyssomyia whitmani (Antunes \& Coutinho) (Psychodidae: Phlebotominae) natural infected by Leishmania infantum in Argentina. Acta Trop. 2015; 152:181-4.

39 Nieves E, Pimenta PF. Development of Leishmania (Viannia) braziliensis and Leishmania (Leishmania) amazonensis in the sand fly Lutzomyia migonei (Diptera: Psychodidae). J Med Entomol. 2000;37 (1):134-40.

40 Hashiguchi Y, Chiller T, Inchausti A, et al. Phlebotomine sandfly species in Paraguay and their infection with Leishmania. Ann Trop Med Parasitol. 1992;86(2):175-80.
41 Salomon OD, Travi BL, Segura EL. Note on sand flies associated with a tegumentary leishmaniasis focus in Salta, Argentina, 1988. Rev Inst Med Trop Sao Paulo. 1995;37(1):555-6.

42 Chaves LF, Pascual M. Climate cycles and forecasts of cutaneous leishmaniasis, a nonstationary vector-borne disease. PLoS Med. 2006;3(8):1320-8.

43 Donalisio MR, Peterson AT, Costa PL, et al. Microspatial distributional patterns of vectors of cutaneous leishmaniasis in Pernambuco, northeastern Brazil. J Trop Med. 2012;2012:17-9. 